\title{
Evaluation of acute and sub-acute oral toxicity of the aqueous extract of Aquilaria malaccensis leaves in Sprague Dawley rats
}

\author{
Redzuan Nul Hakim Abdul Razak ${ }^{\text {a,e }}$, Suzanah Abdul Rahman ${ }^{a}$, Asmah Hanim Hamdan ${ }^{\mathrm{b}}$, Roszaman \\ Ramlic, Muhammad Lokman Md Isa ${ }^{\mathrm{de} e^{*}}$, Hussin Muhammad ${ }^{\mathrm{f}}$, Nik Fakhuruddin Nik Hassan ${ }^{\mathrm{g}}$ \\ ${ }^{a}$ Department of Biomedical Sciences, Kulliyyah of Allied Health Sciences, International Islamic University Malaysia, 25200 Kuantan, Pahang, \\ Malaysia \\ ${ }^{b}$ Department of Pathology and Laboratory Medicine, Kulliyyah of Medicine, International Islamic University Malaysia, 25200 Kuantan, Pahang, \\ Malaysia \\ 'In vitro Fertilization (IVF) Centre, Kulliyyah of Medicine, International Islamic University Malaysia, 25200 Kuantan, Pahang, Malaysia \\ ${ }^{d}$ Department of Basic Medical Sciences, Kulliyyah of Nursing, International Islamic University Malaysia, 25200 Kuantan, Pahang, Malaysia \\ 'IIUM Molecular and Cellular Biology Research Cluster (iMoleC), International Islamic University Malaysia, 25200 Kuantan, Pahang, \\ Malaysia

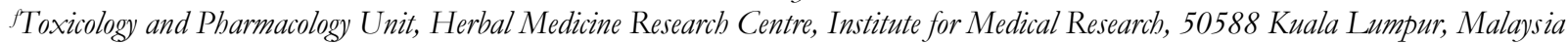 \\ ${ }^{g}$ Forensic Science Programme, School of Health Sciences, Universiti Sains Malaysia, 11800 Penang, Malaysia
}

\section{Received 8th August 2018 / Accepted 14th December 2018}

\begin{abstract}
Aquilaria malaccensis or commonly known as 'gaharu' is a species of Aquilaria genus and belongs to the Thymelaeaceae family. It is widely distributed in Malaysia, Indonesia, and the Borneo Islands. Traditionally, its leaves were used to relieve bruises and studies have shown that they function as an antioxidant, aphrodisiac, and tranquilizer. Despite its proven beneficial medicinal properties, information regarding its toxicity is limited. Therefore, we performed a safety evaluation on the aqueous $A$. malaccensis leaves extract (AMAE) in Sprague Dawley rats. The assessment of acute toxicity based on the Organization for Economic Cooperation and Development (OECD) Guideline 420 revealed that AMAE did not influence mortality, clinical appearance, body weight gain, or necropsy findings at a dose of $2000 \mathrm{mg} / \mathrm{kg}$ body weight. In the sub-acute toxicity, all doses did not significantly modify the body weight and food and water intake. In male rats treated with $2000 \mathrm{mg} / \mathrm{kg}$, there was a significant reduction in the relative weight of liver. Not only that, an increase in alkaline phosphatase and alanine transaminase was also observed in different groups among the female rats. A significant decrease in the creatinine level was also seen among male rats administered with different doses of AMAE. In both sexes, histopathological analysis had shown abnormalities in the liver and kidney of rats treated at the dose of $2000 \mathrm{mg} / \mathrm{kg}$. In conclusion, the $50 \%$ lethal dose $\left(\mathrm{LD}_{50}\right)$ of AMAE was estimated to be greater than $2000 \mathrm{mg} / \mathrm{kg}$. In sub-acute duration, the findings suggested that AMAE administered orally is slightly toxic at higher doses $(2000 \mathrm{mg} / \mathrm{kg})$ and could provoke functional and structural changes in the kidney and liver of rats. Thus, the extract should be used with caution.
\end{abstract}

Keywords: Aquilaria malaccensis, aqueous extract, acute toxicity, sub-acute toxicity

\section{INTRODUCTION}

Over the past few decades, the popularity of plant remedies has become more substantial and vital to various parts of the world. Despite the useful and medical benefits of the plants, some of the phytochemical compounds might pose lethal threats to human. Obviously, commonly

\footnotetext{
* Author for correspondence: Muhammad Lokman Md. Isa, Department of Basic Medical Sciences for Nursing, Kuliyyah of Science, International Islamic University Malaysia, Bandar Indera Mahkota, 25200 Kuantan, Pahang, Malaysia. Email - lokman@iium.edu.my
} 
consumed plant preparations have limited data on their efficacy and potential toxicity. It must be clearly understood that all plant products should not be falsely considered as safe as they are natural. Some chemical constituents in plants may be safe to the plant but it might be deleterious to human. In addition, some chemical constituents present as naturally safe may exhibit toxic effects at a certain dose or prolonged exposure (Bode \& Dong, 2014).

Toxicity assessment is an approach to evaluate the adverse effects of elements that are intended to be used or consumed by humans. These elements could be from chemical, physical, biological, animals, or the environment. The emergence of toxicity in natural products could be intrinsic, extrinsic, and from other contributing factors (Knöss, 2017). The phytochemical or metabolites in a plant could contribute to its intrinsic toxicity. The extrinsic toxicity can be derived from pesticides, environmental pollutants, preservatives, and adulterants. In addition, toxicity can also be acquired from the processing procedures such as sun drying, roasting, frying, steaming, and fumigating. Herbdrug and herb-herb interactions including prolonged consumption and high dosage could also play important roles in triggering adverse effects (Cock, 2015).

A. malaccensis is a native species of Aquilaria in Malaysia, Indonesia, and Thailand. It is classified under the family Thymelaeaceae and one of the agarwood-producing trees. It is locally known as karas, engkaras, gaharu, or depu (Lim \& Noorainie, 2010). Mitra, Orbell and Muralitharan (2007) addressed the local ethnomedicinal use of A. malaccensis in treating general dropsy or oedema using $A$. malaccensis root infusion while its leaves are rubbed over swollen hands and legs of a dropsical patient. This plant has gained enormous interest among researchers due to its antioxidant activity (Huda, Munira, Fitrya, \& Salmah, 2009; Miniyar et al., 2008; Nik Wil, Mohd Omar, Awang@Ibrahim, \& Tajuddin, 2014; Ray, Leelamanit et al., 2014; Sattayasai et al., 2012; Tay et al., 2014), hepatoprotective effect (Vakati et al., 2013), anticancer activity (Ibrahim et al., 2011), antidiabetic (Zulkifle et al., 2013), and antimicrobial activity (Saad S Dahham et al., 2015; Kamonwannasit et al., 2013). Its essential oil can act as mosquito larvicidal and repellent (Zaridah,
Nor Azah, \& Rohani, 2006). These medicinal activities could be attributed to the presence of various phytoconstituents in the extracts.

An array of chemical classes including terpenoids, xanthonoids, flavonoids, benzophenones, phytosterols, phenolic acids, and fatty acids can be found in Aquilaria leaves. A phytochemical finding by Khalil et al. (2013) revealed the presence of flavonoids, tannins, alkaloids, triterpenoids and saponins in methanol extract of $A$. malaccensis leaves. Steroids were also identified in both methanol and water extracts of A. malaccensis leaves (Nik Wil et al., 2014). Acetaminophen or its synthetic form, 4'hydroxyacetanilide also available in the leaves extract of A. malaccensis (Afiffudden, Alwi, \& Hamid, 2015). Various phytoconstituents can be isolated from $A$. malaccensis leaves which can contribute to the health and well-being of humans.

Despite its various beneficial pharmacological activities, its potential health risk might have been overlooked. To date, several toxicity analyses of Aquilaria species were conducted either in vivo or in vitro. Several studies reported no evident toxicity effect was detected following single oral administration of $A$. crassna leaves extract (Saad Sabbar Dahham et al., 2016; Ghan et al., 2016; Kamonwannasit et al., 2013). Meanwhile, an ethanol extract of $A$. agallocha leaves was reported to be non-toxic on single oral administration in female Wistar rats at a dose of $2000 \mathrm{mg} / \mathrm{kg}$ (Vakati et al., 2013). Kaempferol, an isolated constituent of chloroform extract of $A$. subintegra stem, exhibited no cytotoxicity effect on various human cell lines and the lethal concentration (LC $\left.{ }_{50}\right)$ of the Brine Shrimp Lethality Assay (BSLA) was $762.41 \mu \mathrm{g} / \mathrm{ml}$ (Bahrani et al., 2014). Leaves extract of $A$. sinensis, another species of Aquilaria, demonstrated no acute toxicity and genotoxic effects (Li et al., 2015). Musir, Winarti, \& Siti Hasnah (2016) described that the $\mathrm{LC}_{50}$ of $70 \%$ ethanol extract of non-inoculated $A$. beccariana leaves was $113.73 \mathrm{ppm}$.

An acute and sub-acute toxicity study of $A$. malaccensis methanol leaves extract suggested the $\mathrm{LD}_{50}$ was higher than $2000 \mathrm{mg} / \mathrm{kg}$ and the effective dose was $500 \mathrm{mg} / \mathrm{kg}$ (Zulkifle et al., 2018). Therefore, this is the very first toxicity study of aqueous extract of $A$. malaccensis carried out on Sprague Dawley rats to define its safety 
profile and ascertain its potential adverse effects as a key stepping stone for further development of the extract.

\section{MATERIALS AND METHODS}

Plant collection and identification. The leaves were collected in the morning ( 9 a.m. to 10 a.m.) from $A$. malaccensis tree plantation in the Forest Research Institute Malaysia (FRIM) Research Station, Maran Pahang. The leaves were collected between the month of March and April 2016. The leaves' compositions were identified and authenticated by a botanist from Universiti Kebangsaan Malaysia (UKM). The specimen voucher PIIUM 0296 was prepared by and deposited at the Natural Medicinal Product Centre, Kulliyyah of Pharmacy, IIUM.

Preparation of the extract. The aqueous extraction of $A$. malaccensis leaves (AMAE) was performed using hot water extraction method as established by the Phytochemistry Unit, Herbal Medicine Research Centre, Institute for Medical Research. Fresh leaves samples were dried in a solar drying oven and grinded in an electrical grinder to produce the powder form. $150 \mathrm{~g}$ of dried leaves powder was soaked in $1500 \mathrm{ml}$ of $40^{\circ} \mathrm{C}$ hot ultra-pure distilled water and left to fully immerse for 60 minutes followed by filtration through a Whatman No.1 filter paper. The previous steps were repeated twice. The combined filtrates were filled into a plastic centrifuge test tube and stored in a $-80^{\circ} \mathrm{C}$ freezer, and the resulting frozen filtrates were freeze-dried in continuous operation for 144 hours. The extract powder was brown in colour and had a leafy smell with a sweet odour. The powder extract was stored at room temperature in an airtight bottle until further use. The extract was reconstituted in distilled water to obtain the required doses for administration in rats.

Experimental animal. Sprague Dawley rats (2-3 months old and weight between 150-200 g) were used for both acute and sub-acute toxicity tests. 8 female rats (4 rats for sighting study and 4 rats for main study) were used for the acute toxicity study and 40 rats (20 males and 20 females) for the sub- acute toxicity study. All rats were housed singly in polypropylene cages with steel grill covers and bedded with corncob. The rats were kept at room temperature $\left(22 \pm 2^{\circ} \mathrm{C}\right)$, with $50 \pm 10 \%$ humidity, and a cycle of $12 \mathrm{~h}$ light and $12 \mathrm{~h}$ dark. Standard laboratory animal feed and water were provided ad libitum. Rats were acclimatized to the experimental conditions for a period of one week prior to dosing. All research procedures and animals were approved by the Institutional Animal Care and Use Committee (IACUC-IIUM) with approval number IIUM/ IACUC Approval/ 2016/ (9) (57).

Acute toxicity study design. The acute toxicity study design was in accordance with the OECD Guideline 420 with fixed dose (Organisation for Economic Co-operation and Development, 2001b). This study consisted of 2 distinct phases named the sighting study and the main study. All rats were abstained from food overnight prior to dosing. The rats' body weight was measured followed by extract administration. Food was continually withheld for a further 3-4 hours post administration. The sighting study was intended to identify the suitable starting dose for the main study. A total of four female rats were used in the sighting study. Based on Adamson (2016) and Schlede et al. (2005), the fixed dose levels of 5, 50, 300 , and $2000 \mathrm{mg} / \mathrm{kg}$ body weight were selected as starting doses to determine any evident toxicity signs. The lowest dose of AMAE $(5 \mathrm{mg} / \mathrm{kg}$ body weight) was administered to the first rat. The rat was monitored closely for the first 30 minutes followed by hourly observations for four hours. Observation parameters included skin and fur changes, eyes and mucous membrane secretion, salivation, and locomotor activity. The rat was observed for 24 hours and, if there is no mortality recorded, another rat is administered for the next dose level. Similar procedures were performed throughout the dosing study. The highest dose without mortality was selected as the tested dose for the main study. As for the main study, five rats were subjected to administration of the selected dose. The five rats were made up of one rat from the sighting study dosed at the selected dose together with an additional four rats. All rats were kept and observed for the following 14 days. All life phase parameters were recorded such as daily body weight and food and water intake. All rats 
were made to fast overnight and only had access to water. Rats were weighed prior to necropsy with pentobarbital injection intraperitoneally at a dose of $80 \mathrm{mg} / \mathrm{kg}$ body weight. The rats were dissected and vital organs were harvested and weighed. All organs were examined grossly and fixed in $10 \%$ neutral buffered formalin for histopathological processing.

\section{Sub-acute toxicity study design. The OECD} Guideline 407 with repeated dose 28-day oral was used as a study design (OECD, 2008). Each group comprised of 5 male rats and 5 female rats. The control group was given distilled water while the three different doses of AMAE (20, 200 and 2000 $\mathrm{mg} / \mathrm{kg}$ ) were administered daily via oral gavage for 28 days. All rats were closely monitored to observe for any evident clinical signs of toxicity during the administration period. Daily body weight and weekly food and water intake were measured and recorded. All rats were made to fast overnight and only had access to water. All rats were weighed prior to being anaesthetized with a pentobarbital injection intraperitoneally at a dose of $40 \mathrm{mg} / \mathrm{kg}$ body weight. Under the anaesthetized condition, blood was withdrawn from the rats via retro-orbital venous puncture for biochemical analyses. $4 \mathrm{ml}$ of blood were collected into a plain tube (yellow cap). The rats were necropsied and dissected. The vital organs were trimmed, weighed, and harvested for gross examination. Only the kidney and liver were subjected to further histopathological finding.

Biochemical analysis of blood serum. Blood samples were collected into plain tubes and were centrifuged for 15 mins at 3,000 rpm to obtain the serum. The serum was analysed using a blood analyser for renal profile and liver profile. The value for total protein, albumin, urea, and creatinine were recorded to determine the biochemical status of the kidney. The liver profile was evaluated based on alkaline phosphatase, aspartate transferase, and alanine transaminase..

Histological analysis. The organs were cut and trimmed according to the recommendation guideline for organ sampling and trimming by the European Registry of Industrial Toxicology Animal Data (RITA) and North American Control Animal Database (NACAD) (Kittel et al.,
2004; Morawietz et al., 2004; Ruehl-Fehlert et al., 2003). The liver and kidney samples were collected and fixed in 10\% neutral buffered formalin. The organs were processed following the routine histological process and embedded in paraffin to produce tissue blocks. The tissue blocks were sectioned at $4 \mu \mathrm{m}$ of thickness and stained in hematoxylin and eosin (H\&E). The staining protocol was adopted from the Department of Pathology and Laboratory Medicine, Kulliyyah of Medicine with several modifications. The kidney and liver were analysed for histological abnormalities through light microscopy. Both organs were evaluated qualitatively based on the parameters or changes illustrated by Aroud (2014). The kidney was assessed based on the formation of cytoplasmic vacuolation and pyknotic nuclei while the liver was evaluated for vascular congestion and lymphocytic infiltration.

Statistical analysis. All data were assessed for normality using the Test of Normality. A parametric test, one-way analysis of variance (ANOVA), was used for normally distributed data followed by the Post-Hoc test. Dunnett's test was used if equal variance is not assumed while Least Significance Difference (LSD) test was used if equal variance is assumed. The not normal distributed data were analysed using KruskalWallis test followed by the Dunn-Bonferroni pairwise comparisons if there were significant trends. All data were considered statistically significant when $\mathrm{p}<0.05$. The parametric data were expressed as mean \pm standard deviation (SD) and the median (interquartile range) was recorded for non-parametric data. The analyses were performed using SPSS version 25.

\section{RESULTS}

Acute toxicity. All female rats survived until the necropsy day. None of the rats displayed signs of toxicity throughout the observation period. The colour of stools and urine were normal. Therefore, in accordance with OECD guideline, the $\mathrm{LD}_{50}$ is greater than the highest dose used in this study, $2000 \mathrm{mg} / \mathrm{kg}$ body weight. The body weight of rats in all groups increased consistently 
throughout the 14 days and no significant variations were observed. There was no change in food and water intake of female rats administered with AMAE at the highest dose, $2000 \mathrm{mg} / \mathrm{kg}$. The increasing pattern of food and water intake was recorded during the 2 -week observation period. Macroscopic evaluation of the organs did not reveal any abnormality. Histopathological analysis of the kidney and liver showed no histological changes in the organs that might indicate abnormality as shown in Figure 1.

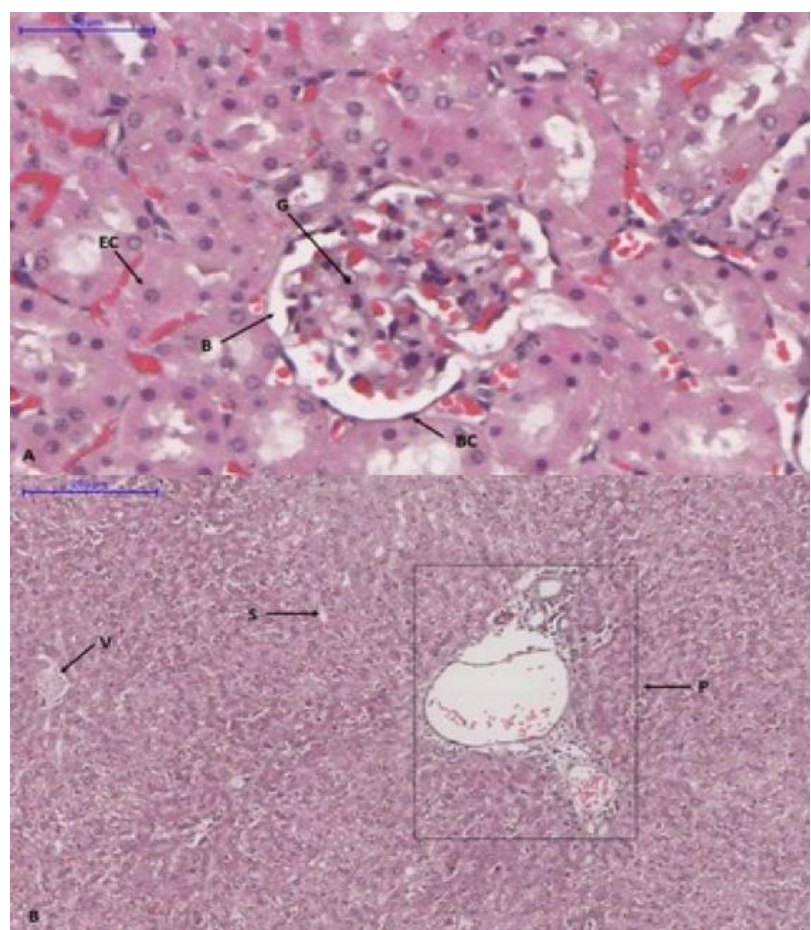

Figure 1. (A) Photomicrograph of kidney section from acute dose of AMAE $2000 \mathrm{mg} / \mathrm{kg}$ demonstrating normal and intact glomerulus and tubular epithelial cells (H\&E stain, X40). (B) Photomicrograph of liver sections from acute dose of AMAE $2000 \mathrm{mg} / \mathrm{kg}$ showing portal tract which contains central vein and bile duct (H\&E stain, X10). B: Bowman's space, BC: Bowman's capsule, EC: Tubular epithelial cell, G: Glomerulus, P: Portal tract, S: Sinusoid, V: Hepatic venule.

Sub-acute toxicity. All rats administered with AMAE at doses of 0 (control), 20, 200, and 2000 $\mathrm{mg} / \mathrm{kg}$ body weight survived with no evident clinical changes throughout the treatment period until necropsy on day 29. All rats displayed good health status until the day of necropsy. There were no changes in body weights and body weight gains in all treated groups. Food and water intake were recorded in similar fashion among the treated groups and the control group. Statistical analysis did not show any significant difference among groups $(p>0.05)$. The general health parameters of the rats were tabulated in Table 1.

Absolute and relative organs weight. Both absolute and relative organ weights in all groups were recorded as normal except the relative organ weight of liver in male rats treated with 2000 $\mathrm{mg} / \mathrm{kg}$ body weight which was lower than control and other treated groups. This change was significantly different $(p<0.05)$. The relative organ weights of adrenal glands, kidneys, and liver were presented in Table 2 .

Clinical biochemistry of blood serum. The renal profile of the rats was assessed based on the value of total protein, albumin, globulin, urea, and creatinine. There were no significant differences between all groups for all renal parameters in male and female rats except a significantly elevated level of globulin in AMAE 2000 of male rats and significant reduction of creatinine in male rats of all AMAE administered groups. Meanwhile, the female rats in AMAE 200 exhibited an increase in urea level. The liver profile of the rats was evaluated based on the value of three liver enzymes named alkaline phosphatase, aspartate transferase, and alanine transaminase. In male rats, the level of alkaline phosphatase and alanine transaminase was not significant between all groups except for aspartate transferase, which was at a high significant level for both AMAE 200 and 2000. Meanwhile, in female rats, alanine transaminase was recorded at a significantly high level for AMAE 200 and 2000. Only AMAE 200 indicated significant elevated level of aspartate transferase. The detailed renal and liver profiles were described in Table 3. 
Table 1. The vital general health parameters of rats in control and administered with AMAE for 28 days.

\begin{tabular}{|l|c|c|c|c|}
\hline \multirow{2}{*}{ General parameters } & \multicolumn{4}{|c|}{ Administration } \\
\cline { 2 - 5 } & Control & AMAE 20 & AMAE 200 & AMAE 2000 \\
\hline \multicolumn{5}{|c|}{ Male } \\
\hline Weekly water intake $(\mathrm{ml})$ & $293.00(14.56)^{\mathrm{np}}$ & $279.75(36.25)^{\mathrm{np}}$ & $296.25(48.38)^{\mathrm{np}}$ & $244.25(56.00)^{\mathrm{np}}$ \\
\hline Weekly food intake $(\mathrm{ml})$ & $178.02 \pm 4.66$ & $165.91 \pm 7.54$ & $161.60 \pm 5.29$ & $154.86 \pm 3.64$ \\
\hline Daily body weight $(\mathrm{g})$ & $260.68 \pm 3.53$ & $246.69 \pm 7.45$ & $249.33 \pm 11.62$ & $257.68 \pm 9.12$ \\
\hline Body weight gain $(\mathrm{g})$ & $124.31 \pm 7.71$ & $101.88 \pm 15.95$ & $78.47 \pm 11.44$ & $82.50 \pm 10.65$ \\
\hline \multicolumn{5}{|c|}{ Female } \\
\hline Weekly water intake $(\mathrm{ml})$ & $210.80 \pm 13.00$ & $225.60 \pm 0.8 .62$ & $189.75 \pm 7.24$ & $219.85 \pm 12.42$ \\
\hline Weekly food intake $(\mathrm{ml})$ & $132.71 \pm 7.25$ & $142.16 \pm 5.08$ & $129.92 \pm 5.75$ & $131.74 \pm 8.39$ \\
\hline Daily body weight $(\mathrm{g})$ & $174.48 \pm 7.53$ & $194.48 \pm 7.29$ & $195.63 \pm 7.29$ & $189.96 \pm 11.48$ \\
\hline Body weight gain $(\mathrm{g})$ & $81.75 \pm 10.64$ & $69.62 \pm 6.39$ & $52.86 \pm 5.34$ & $59.09 \pm 7.16$ \\
\hline
\end{tabular}

Values are expressed as Mean \pm SEM

npValues are expressed as Median (IQR)

Table 2. The relative organ weight of rats in control and administered with AMAE for 28 days.

\begin{tabular}{|l|c|c|c|c|}
\hline \multirow{2}{*}{ Relative organ weight (\%) } & \multicolumn{4}{|c|}{ Treatment } \\
\cline { 2 - 5 } & Control & AMAE 20 & AMAE 200 & AMAE 2000 \\
\hline \multicolumn{5}{|c|}{ Male } \\
\hline Right adrenal & $0.007 \pm 0.0004$ & $0.008 \pm 0.0007$ & $0.008 \pm 0.0006$ & $0.009 \pm 0.0002$ \\
\hline Left adrenal & $0.008 \pm 0.0001$ & $0.008 \pm 0.0006$ & $0.009 \pm 0.0008$ & $0.01 \pm 0.0009$ \\
\hline Right kidney & $0.47 \pm 0.02$ & $0.43 \pm 0.01$ & $0.49 \pm 0.02$ & $0.45 \pm 0.01$ \\
\hline Left kidney & $0.46 \pm 0.03$ & $0.43 \pm 0.02$ & $0.49 \pm 0.02$ & $0.44 \pm 0.01$ \\
\hline Liver & $3.94 \pm 0.12$ & $3.66 \pm 0.09$ & $3.85 \pm 0.20$ & $3.37 \pm 0.08^{*}$ \\
\hline \multicolumn{5}{|l|}{ Female } \\
\hline Right adrenal & $0.02(0.01)^{\mathrm{np}}$ & $0.01(0.01)^{\mathrm{np}}$ & $0.01(0.00)^{\mathrm{np}}$ & $0.01(0.01)^{\mathrm{np}}$ \\
\hline Left adrenal & $0.02(0.02)^{\mathrm{np}}$ & $0.02(0.00)^{\mathrm{np}}$ & $0.02(0.00)^{\mathrm{np}}$ & $0.02(0.07)^{\mathrm{np}}$ \\
\hline Right kidney & $0.46 \pm 0.02$ & $0.43 \pm 0.01$ & $0.45 \pm 0.02$ & $0.46 \pm 0.02$ \\
\hline Left kidney & $0.44(0.10)^{\mathrm{np}}$ & $0.40(0.11)^{\mathrm{np}}$ & $0.42(0.07)^{\mathrm{np}}$ & $0.47(0.05)^{\mathrm{np}}$ \\
\hline Liver & $4.00(0.27)^{\mathrm{np}}$ & $3.82(0.70)^{\mathrm{np}}$ & $3.55(0.52)^{\mathrm{np}}$ & $3.73(0.42)^{\mathrm{np}}$ \\
\hline
\end{tabular}

Values are expressed as Mean \pm SEM

npValues are expressed as Median (IQR)

${ }^{*} \mathrm{p}<0.05$ in comparison to control

\section{Histopathological analysis of kidney and} liver. There were no marked abnormalities observed in gross examination of kidney and liver in all groups. However, histopathological examination revealed several cellular changes in kidneys and liver. Both kidneys and liver in the control group and treated groups (20 and 200 $\mathrm{mg} / \mathrm{kg}$ ) displayed normal morphology and arrangement. Kidney histological sections of the rats from the highest dose displayed cytoplasmic vacuolation and pyknotic nuclei as shown in Figure 2. Changes in both parameters including lymphocytic infiltration and vascular congestion for liver were observed in the group treated with $2000 \mathrm{mg} / \mathrm{kg}$ body weight as demonstrated in Figure 3. Table 4 summarized the histological changes recorded in the control and treated groups. 
Table 3. The kidney and liver clinical biochemistry of rats in control and administered with AMAE for 28 days.

\begin{tabular}{|l|c|c|c|c|}
\hline \multirow{2}{*}{ Serum parameters } & \multicolumn{4}{c|}{ Administration } \\
\cline { 2 - 5 } & Control & AMAE 20 & AMAE 200 & AMAE 2000 \\
\hline \multicolumn{5}{|c|}{ Male $^{\mathrm{a}}$} \\
\hline Total protein $(\mathrm{g} / \mathrm{dL})$ & $4.84 \pm 0.13$ & $4.68 \pm 0.12$ & $5.04 \pm 0.11$ & $5.22 \pm 0.18$ \\
\hline Albumin $(\mathrm{g} / \mathrm{dL})$ & $2.74 \pm 0.07$ & $2.78 \pm 0.09$ & $2.94 \pm 0.07$ & $2.88 \pm 0.08$ \\
\hline Globulin & $21.00 \pm 0.71$ & $19.00 \pm 0.41$ & $21.00 \pm 0.63$ & $23.40 \pm 1.08^{*}$ \\
\hline Urea $(\mathrm{mmol} / \mathrm{L})$ & $7.86 \pm 0.77$ & $7.60 \pm 0.45$ & $7.28 \pm 0.57$ & $7.38 \pm 0.44$ \\
\hline Creatinine $(\mu \mathrm{mol} / \mathrm{L})$ & $0.46 \pm 0.04$ & $0.30 \pm 0.04 *$ & $0.32 \pm 0.02^{*}$ & $0.33 \pm 0.03^{*}$ \\
\hline Alkaline phosphatase $(\mathrm{U} / \mathrm{L})$ & $230.20 \pm 23.06$ & $208.75 \pm 15.26$ & $275.40 \pm 33.42$ & $256.20 \pm 17.37$ \\
\hline Aspartate transferase $(\mathrm{U} / \mathrm{L})$ & $224.80 \pm 26.89$ & $250.25 \pm 20.56$ & $297.60 \pm 11.63 *$ & $311.60 \pm 12.88^{*}$ \\
\hline Alanine transaminase $(\mathrm{U} / \mathrm{L})$ & $39.00 \pm 4.72$ & $52.25 \pm 10.14$ & $54.60 \pm 8.12$ & $50.60 \pm 3.47$ \\
\hline \multicolumn{4}{|c|}{ Female } & \\
\hline Total protein $(\mathrm{g} / \mathrm{dL})$ & $4.72 \pm 0.17$ & $4.78 \pm 0.25$ & $4.96 \pm 0.14$ & $4.96 \pm 0.21$ \\
\hline Albumin $(\mathrm{g} / \mathrm{dL})$ & $2.68 \pm 0.10$ & $2.74 \pm 0.12$ & $2.80 \pm 0.08$ & $2.74 \pm 0.14$ \\
\hline Globulin & $20.40 \pm 0.81$ & $20.40 \pm 1.50$ & $21.60 \pm 0.75$ & $22.40 \pm 0.75$ \\
\hline Urea $(\mathrm{mmol} / \mathrm{L})$ & $7.08 \pm 0.65$ & $7.04 \pm 0.62$ & $9.36 \pm 0.51^{*}$ & $8.32 \pm 0.33$ \\
\hline Creatinine $(\mu \mathrm{mol} / \mathrm{L})$ & $0.40 \pm 0.04$ & $0.35 \pm 0.03$ & $0.44 \pm 0.04$ & $0.39 \pm 0.02$ \\
\hline Alkaline phosphatase $(\mathrm{U} / \mathrm{L})$ & $214.40 \pm 18.91$ & $184.60 \pm 17.12$ & $183.20 \pm 7.83$ & $199.80 \pm 13.47$ \\
\hline Aspartate transferase $(\mathrm{U} / \mathrm{L})$ & $214(75)^{\mathrm{np}}$ & $259(133)^{\mathrm{np}}$ & $341(1220)^{\mathrm{np} *}$ & $312(189)^{\mathrm{np}}$ \\
\hline Alanine transaminase $(\mathrm{U} / \mathrm{L})$ & $36(10)^{\mathrm{np}}$ & $41(16)^{\mathrm{np}}$ & $54(90)^{\mathrm{np} *}$ & $60(11)^{\mathrm{np} *}$ \\
\hline
\end{tabular}

Values are expressed as Mean \pm SEM

npValues are expressed as Median (IQR)

${ }^{*} \mathrm{p}<0.05$ in comparison to control

${ }^{a}$ One missing value, $\mathrm{n}=4$

Table 4. The histological parameters of rats in control and administered with AMAE for 28 days.

\begin{tabular}{|c|c|c|c|c|c|}
\hline \multirow{2}{*}{\multicolumn{2}{|c|}{ Histological parameters }} & \multicolumn{4}{|c|}{ Administration } \\
\hline & & Control & AMAE 20 & AMAE 200 & AMAE 2000 \\
\hline \multicolumn{6}{|c|}{ Male } \\
\hline \multirow{2}{*}{ Liver } & Vascular congestion & No & $\mathrm{No}$ & $\mathrm{No}$ & Yes \\
\hline & Lymphocytic infiltration & $\mathrm{No}$ & $\mathrm{No}$ & $\mathrm{No}$ & Yes \\
\hline \multirow{2}{*}{ Kidney } & Cytoplasmic vacuolation & No & No & No & Yes \\
\hline & Pyknotic nuclei & $\mathrm{No}$ & $\mathrm{No}$ & $\mathrm{No}$ & Yes \\
\hline \multicolumn{6}{|c|}{ Female } \\
\hline \multirow{2}{*}{ Liver } & Vascular congestion & No & No & No & Yes \\
\hline & Lymphocytic infiltration & $\mathrm{No}$ & $\mathrm{No}$ & $\mathrm{No}$ & Yes \\
\hline \multirow{2}{*}{ Kidney } & Cytoplasmic vacuolation & No & No & No & Yes \\
\hline & Pyknotic nuclei & No & No & No & Yes \\
\hline
\end{tabular}




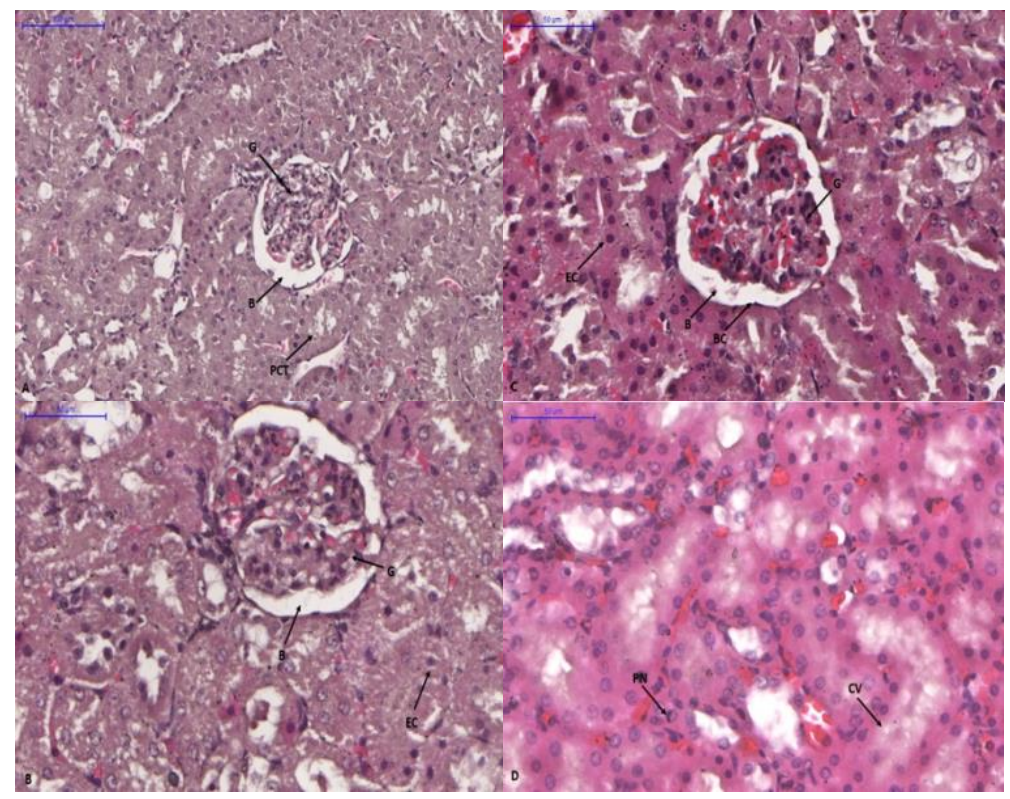

Figure 2. (A) Photomicrograph of kidney section of a control rat in subacute toxicity study of AMAE sacrificed at the end of study period showing normal morphology of glomerulus, tubular epithelial cells and Bowman's space (H\&E stain, X20). (B) Photomicrograph of kidney section of a rat AMAE 20 in subacute toxicity of AMAE sacrificed at the end of study period showing no abnormality (H\&E stain, X40). (C) Photomicrograph of kidney section of a rat AMAE 200 in subacute toxicity study of AMAE sacrificed at the end of study period showing intact cellular arrangements and histology (H\&E stain, X40). (D) Photomicrograph of kidney section of a rat AMAE 2000 in subacute toxicity study of AMAE sacrificed at the end of study period showing cytoplasmic vacuolation and appearance of pyknotic nuclei (H\&E stain, X40). B: Bowman's space, BC: Bowman's capsule, G: Glomerulus, PCT: Proximal convoluted tubule, EC: Tubular epithelial cell, CV: Cytoplasmic vacuolation, PN: Pyknotic nuclei.

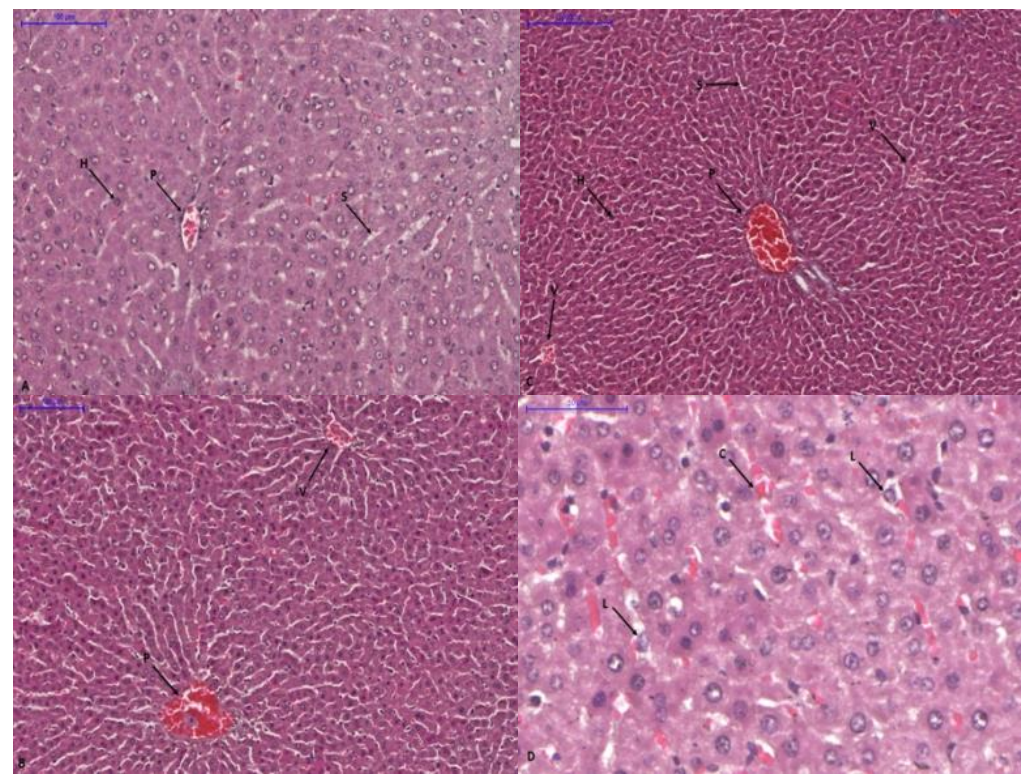

Figure 3. (A) Photomicrograph of liver section of a control rat in subacute toxicity study of AMAE sacrificed at the end of study period exhibiting normal hepatocytes and sinusoids (H\&E stain, X20). (B) Photomicrograph of liver section of a rat AMAE 20 in subacute toxicity of AMAE sacrificed at the end of study period showing no notable abnormality (H\&E stain, X15). (C) Photomicrograph of liver section of a rat AMAE 200 in subacute toxicity study of AMAE sacrificed at the end of study period showing intact cellular arrangements and histology (H\&E stain, X10). (D) Photomicrograph of liver section of a rat AMAE 2000 in subacute toxicity study of AMAE sacrificed at the end of study period showing lymphocytic infiltration and vascular congestion (H\&E stain, X40). H: Hepatocyte, P: Portal tract, S: Sinusoid, V: Hepatic venule, C: Vascular congestion, L: Lymphocytic infiltration. 


\section{DISCUSSION}

Toxicity analysis is a fundamental and paramount step to be undertaken for any preparation intended to be used in humans. This analysis could describe any health hazards and risks associated with potential exposures resulting from its consumption or use. Safety consumption of any herbal preparation is a serious issue that needs to be highlighted. Any claimed bioactivity or medicinal benefits of plant extracts needs to be coupled with a safety analysis as there is uncertainty that the plant is free from the possibility of toxicity (Jordan, Cunningham, \& Marles, 2010).

In the acute toxicity study of AMAE, only female rats were used as the experimental animal. In the light of ethical consideration to minimize the number of experimental animal and reduce variability, only one rat was used per dose in the sighting study and an additional 4 rats for the main study. Sex differences are able to manifest distinct toxicity effects in rats. A female rat has lower detoxification capacity and is more responsive to any toxic elements even at a lower dose (OECD, 2001a).

The mortality and toxicity level of acute oral dose of AMAE were evaluated. After 24 hours and 14 days of observation period, no mortality was recorded up to $2000 \mathrm{mg} / \mathrm{kg}$. Thus, AMAE can be categorised under category- 5 and $\mathrm{LD}_{50}$ value was greater than $2000 \mathrm{mg} / \mathrm{kg}$ in line with Globally Harmonised System of Classification and Labelling of Chemicals. This $\mathrm{LD}_{50}$ finding was similar with the previous acute toxicity analysis of methanol extract of $A$. malaccensis leaves (Zulkifle et al., 2018). In fact, mangiferin that can be found in the Aquilaria species did not exhibit any evident toxicity (Prado et al., 2015).

Daily clinical observations were conducted on the rats for 14 days starting from the first 24 hours prior treatment. The observations were carried out based on Hippocratic signs. Qualitative findings from Hippocratic signs are helpful in preliminary investigation of toxic properties of a substance. Moreover, it can also assist the establishment of a dosing regimen for prolonged pharmacological and toxicological studies (de Azevedo Neta Mahon et al., 2014). In our acute toxicity study, there was no evident adverse clinical signs recorded at any doses tested during the observation period of 14 days. Positive findings during the 14-day observation implied no delayed toxic effect occurred (OECD, 2001b).

Increasing body weight pattern in all groups indicated the normal growth of the rats. This pattern was in line with the consistency in food and water intake percentage of consumption. This positive consistency exhibited the normal metabolism of the rats and the extract did not retard the rats' growth (Mukinda \& Eagles, 2010). Reduction in average food intake could be an indicator for sickness behaviour. This sickness behaviour can also be associated with cognitive disturbances, social withdrawal, anorexia, and lethargy (Shattuck \& Muehlenbein, 2015). Meanwhile, organ weight is an important indication of the pathological and physiological status of animals. Instead of absolute organ weight, relative organ weight or organ-to-body weight ratios is highly useful when body weight confound the organ weight (Michael et al., 2007). The relative organ weight of all vital organs was normal and within the normal range. This implied that AMAE at $2000 \mathrm{mg} / \mathrm{kg}$ did not pose any pathological threat to vital organs like the liver and kidney.

Due to limited data that could be gained from the acute toxicity study, it is important to have more extensive data on repeated administration due to the fact that cumulative toxic effects could occur even at very low doses (Abotsi, Ainooson, \& Gyasi, 2011). Therefore, in this present study, the sub-acute profile of AMAE was assessed in rats using a measurement of body and organ weights, biochemical and histopathological parameters. In the sub-acute toxicity study, both sexes of rat were used to accurately justify any toxic or unwanted changes across genders upon prolonged and consecutive oral treatment. Unlike the single dose treatment of acute toxicity study, prolonged oral treatment might possess different outcomes of several parameters. It is known that continuous intake of any treatment for certain periods of time affects the balance state of several hormones and induces sex specific differences. As an example, different mode of lipid and glucose metabolism among male and female associated with sex specific insulin resistance development (Stanimirovic et al., 2016). 
A study demonstrated that the toxicity of triptolide, an active diterpenoid from Tripterygium wilfordii, was in sex-related pattern. The high distribution of CYP3A2 in male rats accelerates triptolide metabolism including rapid triptolide clearance by male rats liver microsomes up to 5 fold faster than seen in female rats (Liu et al., 2010). Unless it is related to a specific reproductive system, it is vital to put sex differences into consideration as it is a biological variable that might confound the finding. In fact, this consideration can provide a better insight in the pharmacological and toxicological research to enhance the safety evaluation of any compound or extract (Gochfeld, 2016).

It was noted that daily oral administration for 28 days of AMAE up to $2000 \mathrm{mg} / \mathrm{kg}$ did not cause mortality to the rats. In fact, no prominent toxicity signs were recorded during daily observation in post oral treatment. Therefore, it was appropriately justified that AMAE has low toxicity following repeated oral administration and is relatively safe as classified by the OECD guideline. This recent finding was correlated with a previous sub-acute toxicity study of ethanol extract of similar species which reported no mortality and adverse toxicity signs (Zulkifle et al., 2018).

In case of prolonged administration, it is recommended to measure weekly body weight. It is highly sensitive to detect the toxicity of materials with low toxicity level (Jigam et al., 2012). The prolonged administration of AMAE did not cause any alteration in body weight and body weight gain in all treated groups. Similarly, the food intake and water consumption were documented as normal. This scenario indicated that the prolonged extract administration did not disrupt the normal growth and no significant physiological alterations occurred in the rats. The extract may not affect the digestion process of the rats. Our findings on vital health status of rats administered with $A$. malaccensis extract were consistent with the findings of Zulkifle et al. (2018).

Serum biochemical parameter is an essential analysis to evaluate the consequences of drugs on vital organs particularly liver and kidney. The liver is known to metabolize drugs as well as detoxify any toxic elements circulating in the blood. Two transaminase enzymes, aspartate transferase, and alanine transaminase are the important biomarkers for identifying any potential toxic effects and indicating the functional status of the liver. These enzymes are present abundantly in the hepatocytes. In the event of damaging toxic effects, hepatocytes are highly susceptible to injury and leak these enzymes into blood circulation. Any elevation of both transaminases in blood is associated with liver injury (Raina et al., 2015).

In our study, an elevation of aspartate transferase was demonstrated in AMAE 200 and 2000 in male rats. Even though high aspartate transferase can be associated with liver damage, it is still arguable as there was inconsistent and not significant data for alanine transaminase. Aspartate transferase is not a convincing and highly specific marker for liver damage as it is also generated by other tissues like the muscles, heart, and brain (Adeyemi, Akindele, \& Nwumeh, 2010). In addition, aspartate transferase is able to bind with an immunoglobulin that might cause serum aspartate transferase level and can be falsely linked with liver dysfunction (Yi-Chen et al., 2018). On the other hand, in female rats, a significant increase of alanine transaminase was recorded in AMAE 200 and 2000. However, only AMAE 200 showed a significant increase in aspartate transferase level. The presence of possible toxic compounds trigger the liver's adaptation or regenerative response (Schwabe \& Luedde, 2018) such as hepatocyte hypertrophy, rapid production of metabolizing enzyme, and cytoplasmic organelles synthesis to assist the detoxification process following chronic exposure (Meyer, 2001). Notably, relative organ weight of the liver did not show any significant changes as compared to control except a significant reduction in liver relative weight of AMAE 2000. Hepatocytes are highly susceptible to an array of harmful elements that can cause cellular degeneration or atrophy as seen in Jiang et al. (2017). Apoptosis of hepatocytes is a sign of liver injury and closely associated with progression of fibrogenesis and development of cirrhosis (Schwabe \& Luedde, 2018). The significant reduction in liver weight of AMAE 2000 suggested the development of liver cirrhosis which is associated with gradual shrinkage of liver size (Gill, 2018; Nath, Vishwakarma, \& Bhattacharjee, 2016). In relation with the histopathology result of liver, both sexes 
in AMAE 2000 demonstrated notable vascular congestion and lymphocytic infiltration that may correlate with the liver cirrhosis. Liver cirrhosis is characterized by hepatic vasculature distortion that can impair portal and arterial blood supply to the central vein. This impairment diminishes exchanging activities between the hepatic sinusoids and the adjacent liver parenchyma (Sofue, Tsurusaki, \& Murakami, 2017). Despite elevations in serum liver enzymes for AMAE 200, these elevations were very slight and did not correlate with histological findings. It is important to highlight that the absence of notable damage in liver histology can manifest slight alterations in serum liver enzymes (Lee et al., 2015). With all the justifications, it can be suggested that AMAE is likely to be hepatotoxic at a dose of $2000 \mathrm{mg} / \mathrm{kg}$.

Meanwhile, the kidney is also known as a critical target organ for noxious compounds which produce an array of nephrotoxic effects in tubular cells and glomerulus. Its function was evaluated by total protein, albumin, globulin, urea and creatinine levels and an increase in these markers is an indicator of a negative impact on renal function. The globulin level of male rats in AMAE 2000 showed a significant difference in comparison to the control group. Conversely, male rats in all groups administered with AMAE exhibited a significant reduction in creatine level as compared to control. However, it is still vague to conclude AMAE exhibited a nephroprotective effect as it is inconsistent with other renal parameters. To add, a reduction in creatinine could also be associated with muscle wastage (Aouachria et al., 2017) apart from nephroprotective properties. On the contrary, the kidney histology of highest dose of AMAE 2000 $\mathrm{mg} / \mathrm{kg}$ demonstrated the presence of pyknotic nuclei which may indicate cellular necrosis or apoptosis due to inflammation. Considering the safety use of AMAE, it is reasonable to speculate that AMAE 2000 could impair the renal function. It is recommended to conduct a prolonged duration of AMAE administration to accurately evaluate its toxicity towards kidneys

\section{CONCLUSION}

In conclusion, the present study demonstrated that the aqueous extract from $A$. malaccensis is nontoxic with $\mathrm{LD}_{50}>2000 \mathrm{mg} / \mathrm{kg}$. However, subacute administration of aqueous extract from $A$. malaccensis over a period of 28 days and at a higher dose triggered several toxicity effects in rats. At the dose of $2000 \mathrm{mg} / \mathrm{kg}$, there were significant biochemical and histological changes that indicate hepatotoxic and nephrotoxic activities. Thus, in order to limit the adverse effects of the plant extract, it is cautioned to use this plant extract above $2000 \mathrm{mg} / \mathrm{kg}$ dose at a prolonged duration. Indeed, this study offers valuable preliminary data on the toxicity profile of $A$. malaccensis that is surely useful for future in vivo and clinical studies.

In future studies, it is recommended to conduct an extensive prolonged treatment such as sub-chronic and chronic duration. This will provide a better insight of this extract upon prolonged consumption as most of the herbal preparations are intended for extended duration. Upon that notion, it is highly suggested to carry out wide-ranging toxicity to determine the effects of this plant on the prenatal development, reproductive capacity, genetic, and tumor generation.

\section{ACKNOWLEDGEMENTS}

The authors would like to acknowledge the financial support provided by the International Islamic University Malaysia under Research Initiative Grant Scheme (RIGS), Project No. FRGS 15-253-0494.

\section{REFERENCES}

Abotsi, W. K. M., Ainooson, G. K., \& Gyasi, E. B. 2011. Acute and sub-acute toxicity studies of the ethanolic extract of the aerial parts of Hilleria latifolia (Lam.) H. Walt. (Phytolaccaceae) in rodents. West African Journal of Pharmacy 22: 27-35.

Adamson, R. H. 2016. The acute lethal dose $50\left(\mathrm{LD}_{50}\right)$ of caffeine in albino rats. Regulatory Toxicology and Pharmacology 80: 274 276.

Adeyemi, O. O., Akindele, A. J., \& Nwumeh, K. I. 2010. Acute and subchronic toxicological assessment of Byrsocarpus 
coccineus Schum. and Thonn. (Connaraceae) aqueous leaf extract. International Journal of Applied Research in Natural Products 3: 1-11.

Afiffudden, S. K. N., Alwi, H., \& Hamid, K. H. K. 2015. Determination of 4'-Hydroxyacetanilide in leaves extract of Aquilaria malaccencis by High Pressure Liquid Chromatograph. Procedia - Social and Behavioral Sciences 195: 2726-2733.

Aouachria, S., Boumerfeg, S., Benslama, A., Benbacha, F., Guemmez, T., Khennouf, S., Arrar, L., Baghiani, A. 2017. Acute, sub-acute toxicity and antioxidant activities (in vitro and in vivo) of Reichardia picroide crude extract. Journal of Ethnopharmacology 208: 105-116.

Araoud, M., Neffeti, F., Douki, W., Khaled, L., Najjar, M. F., Kenani, A., \& Houas, Z. 2014. Toxic effects of methamidophos on Paraoxonase 1 activity and on rat kidney and liver and ameliorating effects of alphatocopherol. Environmental Toxicology 24(3): 296-303.

Bahrani, H., Mohamad, J., Paydar, M., \& Rothan, H. A. 2014. Isolation and characterisation of acetylcholinesterase inhibitors from Aquilaria subintegra for the treatment of Alzheimer's disease (AD). Current Alsheimer Research 11(2): $1-9$.

Bode, A. M., \& Dong, Z. 2014. Toxic phytochemicals and their potential risks for human cancer. Cancer Prevention Research 8(1): $1-8$.

Cock, I. E. 2015. The safe usage of herbal medicines: counterindications, cross-reactivity and toxicity. Pharmacognosy Communications 5(1): 2-38.

Dahham, S. S., Ahmed Hassan, L. E., Khadeer Ahamed, M. B., Abdul Majid, A. S., Abdul Majid, A. M. S., \& Zulkepli, N. N. 2016. In vivo toxicity and antitumor activity of essential oils extract from agarwood (Aquilaria crassna). BMC Complementary and Alternative Medicine 16(236): 1-11.

Dahham, S. S., Tabana, Y. M., Iqbal, M. A., Ahamed, M. B. K., Ezzat, M. O., Majid, A. S. A., \& Majid, A. M. S. A. 2015. The anticancer, antioxidant and antimicrobial properties of the sesquiterpene $\beta$-caryophyllene from the essential oil of Aquilaria crassna. Molecules 20: 11808-11829.

de Azevedo Neta Mahon, C. P. C., Colodel, E. M., Balogun, S. O., de Oliveira, R. G., \& de Oliveira Martins, D. T. 2014. Evaluation of anti-inflammatory activity of hydroethanolic extract of Dilodendron bipinnatum Radlk. Journal of Ethnopharmacology 155: 665-671.

Ghan, S. Y., Chin, J. H., Thoo, Y. Y., Yim, H. S., \& Ho, C. W. 2016. Acute oral toxicity study of Aquilaria crassna and atocopherol in mice. International Journal of Pharmaceutical Sciences and Research 7(4): 1456-1461.

Gill, S. 2018. Autoimmune hepatitis: Clinical overview and pathological findings. North American Journal of Medicine and Science 11(1): 6-10.

Gochfeld, M. 2016. Sex differences in human and animal toxicology: Toxicokinetics. Toxicologic Pathology 45(1): 172 189

Huda, A. W. N., Munira, M. A. S., Fitrya, S. D., \& Salmah, M. 2009. Antioxidant activity of Aquilaria malaccensis (thymelaeaceae) leaves. Pharmacognosy Research 1(5): 270-273.

Ibrahim, A. H., Al-Rawi, S. S., Abdul Majid, A. M. S., Ab. Rahman, N. N., Abo-Salah, K. M., \& Ab Kadir, M. O. 2011. Separation and fractionation of Aquilaria malaccensis oil using supercritical fluid extraction and the cytotoxic properties of the extracted oil. Procedia Food Science 1: 1953-1959.

Jiang, X., Feng, X., Huang, H., Liu, L., Qiao, L., Zhang, B., \& Yu, W. 2017. The effects of rotenone-induced toxicity via the NF- $x \mathrm{~B}-\mathrm{iNOS}$ pathway in rat liver. Toxicology Mechanisms and Methods 27(4): 318-325.

Jigam, A. A., Abdulrazaq, U. T., Suleiman, R. S., \& Kali, P. S. 2012. Effects of sub-chronic administration of Diospyros mespiliformis Hochst (Ebenaceae) root extracts on some biochemical parameters in mice. Journal of Applied Pharmacentical Science 2(5): 60-64.

Jordan, S. A., Cunningham, D. G., \& Marles, R. J. 2010. Assessment of herbal medicinal products: challenges, and opportunities to increase the knowledge base for safety assessment. Toxicology and Applied Pharmacology 243: 198-216.

Kamonwannasit, S., Nantapong, N., Kumkrai, P., Luecha, P., Kupittayanant, S., \& Chudapongse, N. 2013. Antibacterial activity of Aquilaria crassna leaf extract against Staphylococcus epidermidis by disruption of cell wall. Annals of Clinical Microbiology and Antimicrobials 12(20): 1-7.

Khalil, A. S., Rahim, A. A., Taha, K. K., \& Abdallah, K. B. 2013. Characterization of methanolic extracts of agarwood leaves. Journal of Applied and Industrial Sciences 1(3): 78-88.

Kittel, B., Ruehl-Fehlert, C., Morawietz, G., Klapwijk, J., Elwell, M. R., Lenz, B., O'Sullivan, M. G., Roth, D. R., Wadsworth, P. F. 2004. Revised guides for organ sampling and trimming in rats and mice- Part 2. Experimental and Toxicologic Pathology 55: 413-431.

Knöss, W. 2017. Toxicity of herbal medicines: From past to present to future. In O. Pelkonen, P. Duez, P. M. Vuorela, \& H. Vuorela (Eds.), Toxicology of Herbal Products (pp. 1-10). Switzerland: Springer International Publishing.

Lee, J. S., Kim, Y.-H., Kim, D.-B., Shin, G.-H., Lee, J.-H., Cho, J.H., Lee, B.-Y., Lee, O.-H. 2015. Acute and subchronic $(28$ days) oral toxicity studies of Codonopsis lanceolata extract in Sprague-Dawley rats. Regulatory Toxicology and Pharmacology 71(3): 491-497.

Li, Q., Huang, J., Yang, Y., Chen, M., Liang, Y., \& Chen, X. 2015. Research on the acute toxicity and genetic toxicity of Aquilaria sinensis (Lour.) Gilg. leaf. Chinese Journal of Health Laboratory Technology 25: 1518-1521.

Lim, T. W., \& Noorainie, A. A. 2010. Wood for the Trees: a revien of the agarwood (gaharu) trade in Malaysia. TRAFFIC Southeast Asia. Petaling Jaya, Selangor, Malaysia.

Liu, L., Jiang, Z., Liu, J., Huang, X., Wang, T., Liu, J., Zhang Y., Zhou, Z., Guo, J., Yang, L., Chen, Y., Zhang, L. 2010. Sex differences in subacute toxicity and hepatic microsomal metabolism of triptolide in rats. Toxicology 271: 57-63.

Meyer, S. A. 2001. Overview of hepatotoxicity. Current Protocols in Toxicology 8: 1-6.

Michael, B., Yano, B., Sellers, R. S., Perry, R., Morton, D., Roome, N., Johnson, J. K., Schafer, K. 2007. Evaluation of organ weights for rodent and non-rodent toxicity studies: A review of regulatory guidelines and a survey of current practices. Toxicologic Pathology 35: 742-750.

Miniyar, P. B., Chitre, T. S., Deuskar, H. J., Karve, S. S., \& Jain, K. S. 2008. Antioxidant activity of ethyl acetate extract of Aquilaria agallocha on nitrite-induced methaemoglobin formation. International Journal of Green Pharmacy: 116-117.

Mitra, R., Orbell, J., \& Muralitharan, M. S. 2007. Medicinal plants of Malaysia. Asia-Pacific Biotech News 11(2): 105-110.

Morawietz, G., Ruehl-Fehlert, C., Kittel, B., Bube, A., Keane, K., Halm, S., Heuser, A., Hellmann, J. (2004). Revised guides for organ sampling and trimming in rats and mice- Part 3 . Experimental and Toxicologic Pathology 55(6): 433-449.

Mukinda, J. T., \& Eagles, P. F. K. 2010. Acute and sub-chronic oral toxicity profiles of the aqueous extract of Polygala fruticosa in female mice and rats. Journal of Ethnopharmacology 128: 236-240.

Musir, A., Winarti, W., \& Siti Hasnah, P. S. 2016. Phytochemical screening and toxicity test of BSLT of $70 \%$ ethanol extract of gaharu leaves (Aquilaria beccariana Tiegh.). In The 49th Pokjanas TOI International Seminar (pp. 34-39). Faculty of Pharmacy, Pancasila University. 
Nath, D. C., Vishwakarma, R. K., \& Bhattacharjee, A. 2016. A selection modelling approach to analysing missing data of liver cirrhosis patients. Biometrical Letters 53(2): 83-103.

Nik Wil, N. N. A., Mohd Omar, N. A., Awang@Ibrahim, N., \& Tajuddin, S. N. 2014. In vitro antioxidant activity and phytochemical screening of Aquilaria malaccensis leaf extracts. Journal of Chemical and Pharmaceutical Research 6(12): 688-693.

Organisation for Economic Co-operation and Development. 2001a. Guidance document on acute oral toxicity testing. Paris.

Organisation for Economic Co-operation and Development. 2001b. Test No. 420: Acute Oral Toxicity - Fixed Dose Procedure 420: $1-14$.

Organisation for Economic Co-operation and Development. 2008. Test no. 407: Repeated dose 28-day oral toxicity study in rodents. Drug and Chemical Toxicology 34(1): 77-84.

Prado, Y., Merino, N., Acosta, J., Herrera, J. A., Luque, Y., Hernández, I., Prado, E., Garrido, G., Delgado, R., Rodeiro, I. 2015. Acute and 28-day subchronic toxicity studies of mangiferin, a glucosylxanthone isolated from Mangifera indica L. stem bark. Journal of Pharmacy \& Pharmacognosy Research 3(1): 13-23.

Raina, P., Chandrasekaran, C. V., Deepak, M., Agarwal, A., \& Ruchika, K.-G. 2015. Evaluation of subacute toxicity of methanolic/aqueous preparation of aerial parts of $O$. sanctum in Wistar rats: Clinical, haematological, biochemical and histopathological studies. Journal of Ethnopharmacology 175: 509-517.

Ray, G., Leelamanit, W., Sithisarn, P., \& Jiratchariyakul, W. 2014. Antioxidative compounds from Aquilaria crassna leaf. Mabidol University Journal of Pharmaceutical Sciences 41(4): 54 58.

Ruehl-Fehlert, C., Kittel, B., Morawietz, G., Deslex, P., Keenan, C., Mahrt, C. R., Nolte, T., Robinson, M., Stuart, B. P., Deschl, U. 2003. Revised guides for organ sampling and trimming in rats and mice - Part 1. Experimental and Molecular Pathology 55: 91-106.

Sattayasai, J., Bantadkit, J., Aromdee, C., Lattmann, E., \& Airarat, W. 2012. Antipyretic, analgesic and anti-oxidative activities of Aquilaria crassna leaves extract in rodents. Journal of Ayurveda and Integrative Medicine 3(4): 175-179.

Schlede, E., Genschow, E., Spielmann, H., Stropp, G., \& Kayser, D. 2005. Oral acute toxic class method: A successful alternative to the oral LD 50 test. Regulatory Toxicology and Pharmacology 42: 15-23.

Schwabe, R. F., \& Luedde, T. 2018. Apoptosis and necroptosis in the liver: a matter of life and death. Nature Reviews Gastroenterology and Hepatology.

Shattuck, E. C., \& Muehlenbein, M. P. 2015. Human sickness behavior: Ultimate and proximate explanations. American Journal of Physical Anthropology 157(1): 1-18.

Sofue, K., Tsurusaki, M., \& Murakami, T. 2017. Cirrhotic liver. In Medical Radiology Diagnosis Imaging.

Stanimirovic, J., Obradovic, M., Jovanovic, A., Sudar-Milovanovic, E., Zafirovic, S., Pitt, S. J., Stewart A. J., Isenovic, E. R. 2016. A high fat diet induces sex-specific differences in hepatic lipid metabolism and nitrite/nitrate in rats. Nitric Oxide 54: 51-59.

Tay, P. Y., Tan, C. P., Abas, F., Yim, H. S., \& Ho, C. W. 2014. Assessment of extraction parameters on antioxidant capacity, polyphenol content, epigallocatechin gallate (EGCG), epicatechin gallate (ECG) and iriflophenone 3-C$\beta$-glucoside of agarwood (Aquilaria crassna) young leaves. Molecules 19(8): 12304-12319.

Vakati, K., Rahman, H., Eswaraiah, M. C., \& Dutta, A. M. 2013. Evaluation of hepatoprotective activity of ethanolic extract of Aquilaria agallocha leaves (EEAA) against $\mathrm{CCl}_{4}$ induced hepatic damage in rat. Scholars Journal of Applied Medical Sciences 1(1): 9-12.

Yi-Chen, Wu, M. X., Jie-Liu, Ma, X. J., Shi, J. L., Wang, S. N., Zheng, Z. Q., Guo, J. Y. 2018. Acute and sub-acute oral toxicity studies of the aqueous extract from radix, radix with cortex and cortex of Psammosilene tunicoides in mice and rats. Journal of Ethnopharmacology 213: 199-209.

Zaridah, M. Z., Nor Azah, M. a., \& Rohani, a. 2006. Mosquitocidal activities of malaysian plants. Journal of Tropical Forest Science 18(1): 74-80.

Zulkifle, N. L., Mohd Omar, N. A., Tajudin, S. N., \& Shaari, M. R. 2013. Antidiabetic activities of Malaysian agarwood (Aquilaria Sp.) leaves extract. In Conference on IndustryAcademia Joint Initiatives in Biotechnology.

Zulkifle, N. L., Sabri, N. A., Mhd Omar, N. A., Shaari, M. R., \& Tajuddin, S. N. 2018. Acute and sub-chronic toxicity study of Aquilaria malaccensis leaves extract in Sprague-Dawley rats. Chemistry of Advanced Materials 3(1): 8-15. 